\title{
Visible-Light-Promoted Stereoselective Alkylation by Combining Heterogeneous Photocatalysis with Organocatalysis***
}

\author{
Maria Cherevatskaya, Matthias Neumann, Stefan Füldner, Christoph Harlander, \\ Susanne Kümmel, Stephan Dankesreiter, Arno Pfitzner, Kirsten Zeitler, and Burkhard König*
}

Dedicated to Dr. Wolf-Dieter Haack on the occasion of his 80th birthday

The application of sensitizers to utilize visible light for chemical reactions is an established method. ${ }^{[1]}$ Several recent publications ${ }^{[2]}$ have impressively demonstrated the versatile use of visible light for various transformations, such as the conversion of alcohols to alkyl halides, ${ }^{[3]}$ and $[2+2],{ }^{[4]}$ $[3+2],{ }^{[5]}$ and $[4+2]^{[6]}$ cycloadditions as well as carboncarbon $^{[7]}$ and carbon-heteroatom bond formations. ${ }^{[8]}$ The combination of organocatalysis with visible-light photoredox catalysis using ruthenium or iridium complexes ${ }^{[9]}$ or organic dyes $^{[\mathrm{dd}]}$ as photocatalysts allows for an expansion to enantioselective reactions. ${ }^{[10]}$ Although inorganic semiconductors, such as titanium dioxide, have been widely used for the photocatalytic degradation of organic waste, ${ }^{[11]}$ the number of examples in which they photocatalyze bond formation in organic synthesis is still limited. ${ }^{[12]}$ Kisch and co-workers ${ }^{[13]}$ explored CdS-mediated bond formations, and oxidative $\mathrm{C}-\mathrm{C}$ coupling reactions with titanium dioxide ${ }^{[14]}$ are known. However, bond formations on heterogeneous photocatalysts typically proceed without control of the stereochemistry and mixtures of isomers are obtained. ${ }^{[15,16]}$ We demonstrate herein that the combination of stereoselective organocatalysis with visible-light heterogeneous photoredox catalysis promotes the stereoselective formation of carbon-carbon bonds in good selectivity and yield. The approach combines the advantages of heterogeneous catalysis (robust, simple, and easy-toseparate catalyst material) with the stereoselectivity achieved in homogeneous organocatalysis. ${ }^{[17,18]}$

The enantioselective $\alpha$-alkylation of aldehydes developed by MacMillan et al. ${ }^{[9 a]}$ was selected as a test reaction to apply inorganic heterogeneous photocatalysts (Table 1). Five semiconductors were used: commercially available white $\mathrm{TiO}_{2}$ (1) ${ }^{[19]}$ the same material surface-modified covalently with a Phos-Texas Red dye increasing the absorption of visible light (Phos-Texas-Red-TiO 2 , 2), yellow $\mathrm{PbBiO}_{2} \mathrm{Br}$, which absorbs blue light, and $\mathrm{PbBiO}_{2} \mathrm{Br}$ as bulk material (3) and in nanocrystalline form (4). $\mathrm{TiO}_{2}(\mathbf{1})$ with an average particle

[*] M. Sc. M. Cherevatskaya, M. Sc. M. Neumann, Dr. S. Füldner, M. Sc. C. Harlander, Dipl.-Chem. S. Kümmel, M. Sc. S. Dankesreiter, Prof. Dr. A. Pfitzner, Priv.-Doz. Dr. K. Zeitler, Prof. Dr. B. König Fakultät für Chemie und Pharmazie, Universität Regensburg Universitätsstrasse 31, 93040 Regensburg (Germany) E-mail: burkhard.koenig@chemie.uni-regensburg.de

[**] Financial support from the Deutsche Forschungsgemeinschaft (GRK 1626, chemical photocatalysis) is acknowledged.

(9) Supporting information for this article is available on the WWW under http://dx.doi.org/10.1002/anie.201108721.
Table 1: Enantioselective alkylations using MacMillan's chiral secondary amine and inorganic semiconductors as photocatalysts.

\begin{tabular}{|c|c|c|c|c|c|c|}
\hline Entry & Photocat..$^{[a]}$ & $\lambda[\mathrm{nm}]^{[\mathrm{b}]}$ & $t[\mathrm{~h}]$ & $T\left[{ }^{\circ} \mathrm{C}\right]$ & $\begin{array}{c}\text { Yield } 9 \\
{[\%]^{[c]}}\end{array}$ & $e e[\%]^{[d]}$ \\
\hline 1 & 1 & 440 & 20 & 20 & 55 & 71 \\
\hline 2 & $7^{[e]}$ & 440 & 20 & 20 & 60 & 72 \\
\hline 3 & $7^{[f]}$ & 440 & 3 & 20 & 76 & 74 \\
\hline 4 & 1 & 440 & 20 & -10 & 40 & 83 \\
\hline 5 & 2 & 530 & 20 & 20 & 55 & 72 \\
\hline 6 & 2 & 530 & 20 & -10 & 65 & 81 \\
\hline 7 & 3 & 440 & 20 & 20 & 69 & 71 \\
\hline 8 & 3 & 440 & 20 & -10 & 40 & 84 \\
\hline 9 & 4 & 440 & 20 & 20 & 84 & 72 \\
\hline 10 & 4 & 440 & 20 & -10 & 49 & 83 \\
\hline 11 & $\mathbf{4}^{[f]}$ & 455 & 3 & 20 & 41 & 71 \\
\hline 12 & $4^{[f]}$ & 455 & 10 & -10 & 69 & 80 \\
\hline
\end{tabular}

[a] $64 \mathrm{mg}$ of photocatalyst per $1 \mathrm{mmol}$ of 6 in $2.5 \mathrm{~mL}$ of degassed $\mathrm{CH}_{3} \mathrm{CN}$. [b] High-power LED $(440,455$, or $530 \mathrm{~nm} \pm 10 \mathrm{~nm}, 3 \mathrm{~W}$, LUXEON as indicated). [c] Yield of isolated product. [d] Determined by HPLC on a chiral stationary phase or by NMR spectroscopy using a chiral diol. $^{[27]}[\mathrm{e}]$ Photocatalyst reused. [f] Irradiation in a microreactor in $1.5 \mathrm{~mL}$ of $\mathrm{CH}_{3} \mathrm{CN}$.

size of $21 \mathrm{~nm}$ is a stable and inexpensive semiconductor with a band gap of $3.2 \mathrm{eV}$, but the unmodified powder absorbs only weakly up to $405 \mathrm{~nm}$ as a result of to defects and surface deposits. ${ }^{[20]}$ Its absorption range can be extended into the visible range by structure modification ${ }^{[21]}$ or surface modification with dyes. ${ }^{[22,23]}$ The Texas Red derived dye $\mathbf{1 0}^{[24]}$ (Scheme 1) was covalently anchored on $\mathrm{TiO}_{2}$ yielding $\mathbf{2}$, which absorbs at $560 \mathrm{~nm}$ (see the Supporting Information for the synthesis of $\mathbf{1 0}$ and the characterization of $\mathbf{2}$ ). $\mathrm{PbBiO}_{2} \mathrm{Br} \mathbf{3}$ and $\mathbf{4}$ were prepared by different synthetic routes leading to different particle sizes of the semiconductors: $\mathrm{PbBiO}_{2} \mathrm{Br}$ bulk material 3 with a band gap of $2.47 \mathrm{eV}$ was prepared by hightemperature solid-phase synthesis, ${ }^{[25]}$ while the nanocrystalline material 4 was obtained from synthesis in aqueous solution leading to an average calculated particle size of (28 \pm 6) $\mathrm{nm}$ and an optical band gap of $2.56 \mathrm{eV}$. Yellow CdS (5) has a band gap of $2.4 \mathrm{eV}$ and was prepared as previously reported. ${ }^{[26]}$ 

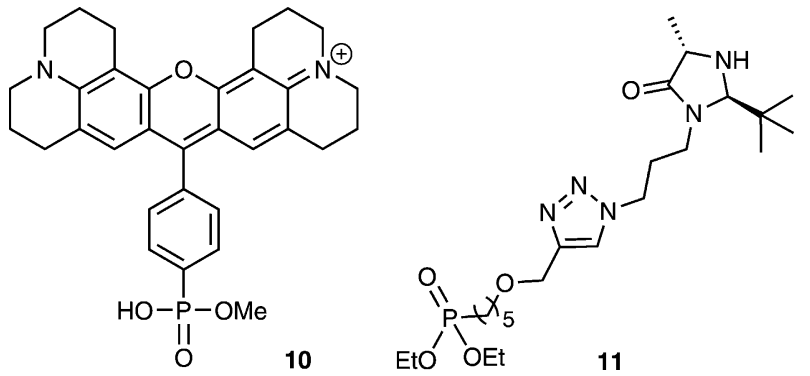

Scheme 1. Compounds for covalent surface immobilization on $\mathrm{TiO}_{2}$ : Phos-Texas-Red (10) and the chiral organocatalyst 11.

The $\alpha$-alkylation of aldehyde $\mathbf{7}$ in the presence of $20 \mathrm{~mol} \%$ of the secondary amine $\mathbf{8}$ as a chiral catalyst and unmodified $\mathrm{TiO}_{2}$ afforded product $\mathbf{9}$ in moderate yield and good enantioselectivity after extended irradiation time (Table 1, entry 1 ), as only a small fraction of the visible light at $440 \mathrm{~nm}$ was absorbed. $\mathrm{TiO}_{2}$ can be reused giving similar results (Table 1 , entry 2 ). With higher light intensity in a microreactor set up (Table 1 , entry 3 ) the reaction time can be reduced to $3 \mathrm{~h}$. Lowering the reaction temperature to $-10^{\circ} \mathrm{C}$ increased the stereoselectivity of the reaction to $83 \% e e$, but slowed down the reaction significantly (Table 1 , entry 4). When surface-modified $\mathrm{TiO}_{2} 2$ was used, the reaction could be run with green light $(530 \mathrm{~nm}$; Table 1 , entries 5 and 6) yielding $65 \%$ product in $81 \%$ ee at $-10{ }^{\circ} \mathrm{C}$. $\mathrm{PbBiO}_{2} \mathrm{Br}(3)$ absorbs in the visible range and catalyzed the reaction with blue light (Table 1, entries 7 and 8). However, its surface area, only $0.17 \mathrm{~m}^{2} \mathrm{~g}^{-1}$, is low compared to that of $\mathrm{TiO}_{2}\left(50 \mathrm{~m}^{2} \mathrm{~g}^{-1}\right)$. This explains the still rather long reaction time. Nanocrystalline $\mathrm{PbBiO}_{2} \mathrm{Br}(4)$ has a larger surface area $\left(10.8 \mathrm{~m}^{2} \mathrm{~g}^{-1}\right)$ and at room temperature and $440 \mathrm{~nm}$ irradiation the product was isolated with a yield of $84 \%$ and $72 \%$ ee after $20 \mathrm{~h}$ (Table 1, entry 9). Again, the stereoselectivity increased to $83 \%$ ee at $-10^{\circ} \mathrm{C}$, but with lower conversion (Table 1 , entry 10). The reaction times could be reduced to 3 and $10 \mathrm{~h}$ (Table 1, entries 11 and 12, respectively), with yields of $69 \%$ and $e e$ values of $80 \%$. The reuse of $\mathbf{4}$ is possible, but black organic surface deposits led to significantly slower conversions.

The mechanism of the alkylation reaction presumably follows the proposed pathway for photoredox catalysis (see the Supporting Information for a scheme). Electron transfer from the conduction band of the semiconductor to the halogenated carbonyl compound results in the loss of a bromide anion and generates the $\alpha$-carbonyl radical, which adds to the enamine obtained by condensation of the chiral catalyst with octanal. The $\alpha$-amino radical is then oxidized by a hole of the valence band yielding the iminium ion that releases catalyst and product.

In an attempt to create a completely heterogeneous catalyst system we prepared the chiral amine phosphonate ester 11 (Scheme 1; see the Supporting Information for the synthesis) and immobilized it on $\mathrm{TiO}_{2}$. However, the catalyst system is inactive and no product formation could be observed under conditions identical to those used before. The close proximity of the secondary amine organocatalyst to the semiconductor surface may lead to its rapid oxidative photodecomposition. The non-immobilized catalyst, mostly present in solution as enamine, will only very rarely encounter the surface as the free amine and is thereby protected from oxidative decomposition.

Our attempts to use CdS (5) for this transformation were not successful. A comparison of the relevant potentials of the widely employed photocatalyst $\left[\mathrm{Ru}(\mathrm{bpy})_{3}\right] \mathrm{Cl}_{2}$ and the investigated semiconductors explains the observation. $\left[\mathrm{Ru}(\mathrm{bpy})_{3}\right]^{+}$ is proposed as the electron donor with a potential of $-1.33 \mathrm{~V}$ (SCE). The conduction band potential of $\mathrm{TiO}_{2}$ at $-2.0 \mathrm{~V}$ (SCE) in acetonitrile is sufficient for this step, while the corresponding reported potential for CdS in acetonitrile of $-1.05 \mathrm{~V}$ may be too low (Figure 1). ${ }^{[28,29]}$ On the other hand, the reductive potential for the quenching of excited $[\mathrm{Ru}-$

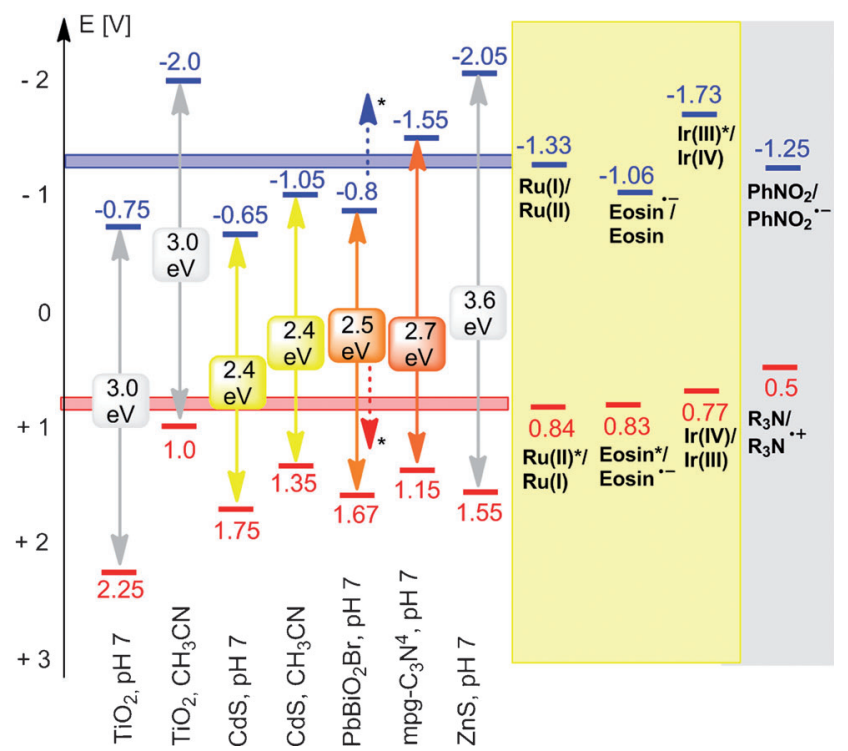

Figure 1. Band gaps (in eV) and redox potentials (in V vs. SCE) of common inorganic semiconductors in comparison with redox potentials of molecular photocatalysts and redox potentials of some photocatalytic key steps. *Estimated change of the flat band potential of $\mathrm{PbBiO}_{2} \mathrm{Br}$ in acetonitrile. Values given for $\mathrm{Ru}$ relate to $\left[\mathrm{Ru}(\mathrm{bpy})_{3}\right]^{2+}$; values for Ir are related to $f a c-\left[\operatorname{Ir}(\text { ppy })_{3}\right]$. bpy $=2,2^{\prime}$-bipyridyl; ppy $=$ phenylpyridyl.

(bpy) $\left.)_{3}\right]^{2+*}$ leading to the oxidation of the $\alpha$-amino radical intermediate is estimated to be $+0.84 \mathrm{~V}$ (SCE), which is matched by the hole potentials (all vs. SCE in acetonitrile) of $\mathrm{TiO}_{2}(+1.0 \mathrm{~V})^{[29,30]}$ and $\mathrm{CdS}(+1.35 \mathrm{~V})$.

The combination of heterogeneous inorganic and homogeneous organic catalysts is applicable to other substrates, such as bromoacetophenone (12a). For the conversion of the more difficult to reduce dinitro benzylbromide $(\mathbf{1 2} \mathbf{b})$ iridium complexes are required in the case of homogeneous photocatalysis. ${ }^{[9 c]}$ However, the estimated conduction band potentials of $\mathrm{TiO}_{2}$ and $\mathrm{PbBiO}_{2} \mathrm{Br}$ in acetonitrile (Figure 1) should be still sufficient and we indeed could observe the clean conversion to the expected products in good yield and high stereoselectivity (Scheme 2). 


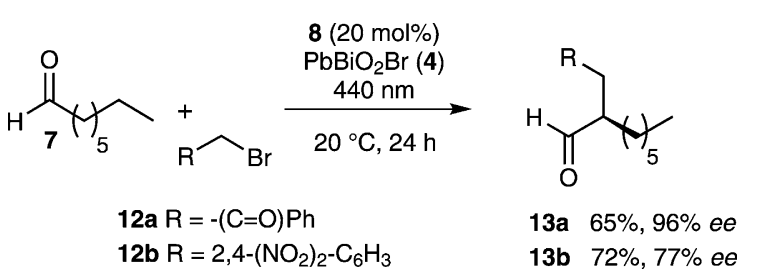

Scheme 2. Alkylation of 7 with bromoacetophenone (12a) in $\mathrm{CH}_{3} \mathrm{CN}$ or with 2,4-dinitrobenzylbromide (12b) in DMSO, using chiral amine 8 , $\mathrm{PbBiO}_{2} \mathrm{Br}(4)$, and blue light.

Recently, several cross-dehydrogenative couplings ${ }^{[31]}$ of tetrahydroisoquinolines by homogeneous photocatalysis using Ir- or Ru-based complexes ${ }^{[5 b, c, 7 d, 8 b, d, 15,31]}$ or organic dyes ${ }^{[33]}$ such as Eosin $\mathrm{Y}^{[8 \mathrm{a}]}$ have been reported. Here the photocatalytic key step is the reductive quenching of the excited chromophore leading to an amine radical cation, which is subsequently converted into an electrophilic iminium species. If one considers the use of inorganic semiconductors for this reaction, the potential of the photogenerated holes in the valence band is of importance. Based on the band gap and its redox potential (see Figure 1) CdS should be a suitable heterogeneous visible-light photocatalyst for oxidations to generate the desired amine radical cation. The combination of proline as the organocatalyst with $\mathrm{CdS}$, as the inorganic photocatalyst, indeed promotes the clean conversion of $\mathrm{N}$ aryltetrahydroisoquinolines $\mathbf{1 4}$ in a photooxidative Mannich type reaction ${ }^{[32 b, 33 a]}$ with ketones $\mathbf{1 5}$ upon irradiation with blue light of $460 \mathrm{~nm}$. The products $\mathbf{1 6} \mathbf{a}-\mathbf{d}$ arising from the reaction with acyclic or cyclic ketones can be obtained in good yields of 76-89\% (Table 2). ${ }^{[34]}$ While the reaction can also be performed successfully in $\mathrm{CH}_{3} \mathrm{CN}$ with a significantly reduced amount of ketone (see Table 2 , entry $1 \mathrm{a}-\mathrm{c}$ ), the reaction is most conveniently run in neat ketone if inexpensive (liquid) ketones are employed.

The flat band potentials of some common inorganic (and organic) semiconductors are summarized in Figure 1. ${ }^{[35]}$ Importantly, at different $\mathrm{pH}$ values and in different organic solvents, these values shift significantly and the currently available data for organic solvents are limited. However, by comparing the semiconductor flat band potentials with the potentials required for catalytic key steps from known photoredox catalysts (e.g. $\mathrm{Ru}$ and Ir complexes, xanthene dyes, etc.), suitable combinations of (inorganic) semiconductors with organocatalysts can be predicted.

We have demonstrated that the appropriate combination of heterogeneous semiconductor photocatalysts with chiral organocatalysts can used to promote different types of stereoselective bond formation by visible-light photocatalysis. The yields and stereoselectivities are comparable to those of previously reported homogeneous reactions using transitionmetal complexes or organic dyes. Electrons are exchanged in the course of the reaction between the chiral reaction intermediates in solution and the semiconductor surface, if the redox potentials of substrates and band gaps match. The covalent immobilization of the organocatalyst on the semiconductor surface leads to its oxidative decomposition and must be avoided.
Table 2: Photocatalytic Mannich reaction of $N$-aryltetrahydroisoquinolines 14 with ketones 15 and L-proline on CdS (5) ${ }^{[\mathrm{a}]}$

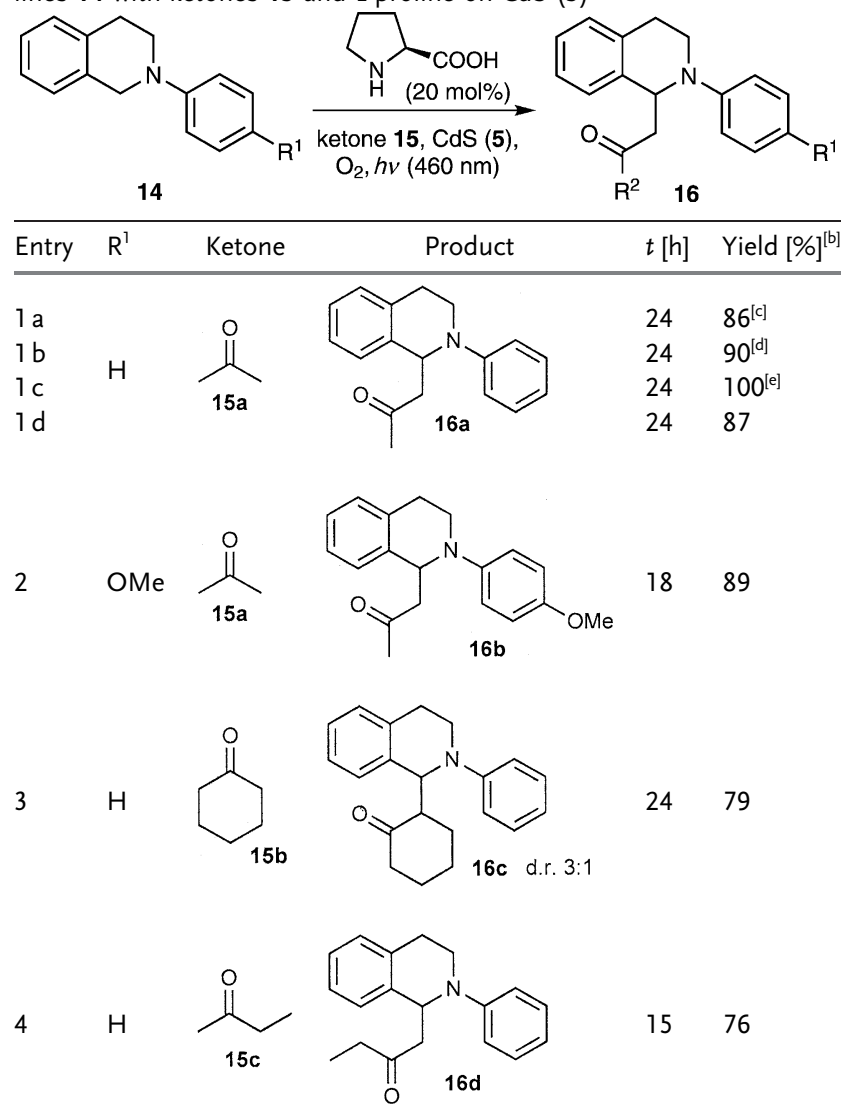

[a] Unless otherwise noted all experiments were performed with amine ( 1 equiv) and L-proline ( 0.2 equiv) in a $5 \mathrm{mg} \mathrm{mL}^{-1}$ mixture of $\mathrm{CdS}$ in neat ketone $\left(c_{\text {amine }}=0.25 \mathrm{~mol} \mathrm{~L}^{-1}\right)$. Reactions were run in Schlenk tubes with an attached oxygen balloon and irradiated with high-power LEDs $(460 \mathrm{~nm})$ for the time indicated. [b] Given yields correspond to isolated product. [c] Reaction performed in $\mathrm{CH}_{3} \mathrm{CN}$ with 2 equiv of acetone; the conversion was determined by $\mathrm{GC}$ analysis. [d] Reaction performed in $\mathrm{CH}_{3} \mathrm{CN}$ with 5 equiv of acetone; the conversion was determined by $\mathrm{GC}$ analysis. [e] Reaction performed in $\mathrm{CH}_{3} \mathrm{CN}$ with 10 equiv of acetone; the conversion was determined by GC analysis.

The good availability of inorganic semiconductors with different band gaps and redox potentials, their simple removal from the reaction mixture, and recycling make them the perfect partners for chiral organocatalysts in stereoselective photocatalysis.

Received: December 11, 2011

Revised: January 17, 2012

Published online: March 13, 2012

Keywords: alkylation - organocatalysis - photocatalysis . semiconductors . visible light

[1] a) A. J. Bard, Science 1980, 207, 139-144; b) F. Teplý, Collect. Czech. Chem. Commun. 2011, 76, 859-917; c) G. Pandey, M. K. Ghorai, S. Hazra, Pure Appl. Chem. 1996, 68, 653.

[2] For recent reviews, see: a) J. M. R. Narayanam, C. R. J. Stephenson, Chem. Soc. Rev. 2011, 40,102-113; b) ref. [1b]; c) T. P. 
Yoon, M. A. Ischay, J. Du, Nat. Chem. 2010, 2, 527-532; d) K. Zeitler, Angew. Chem. 2009, 121, 9969-9974; Angew. Chem. Int. Ed. 2009, 48, 9785-9789.

[3] C. Dai, J. M. R. Narayanam, C. R. J. Stephenson, Nat. Chem. 2011, 3, 140-145.

[4] a) M. A. Ischay, M. E. Anzovino, J. Du, T. P. Yoon, J. Am. Chem. Soc. 2008, 130, 12886-12887; b) J. Du, T. P. Yoon, J. Am. Chem. Soc. 2009, 131, 14604-14605; c) M. A. Ischay, Z. Lu, T. P. Yoon, J. Am. Chem. Soc. 2010, 132, 8572-8574; d) J. Du, L. Ruiz Espelt, I. A. Guzei, T. P. Yoon, Chem. Sci. 2011, 2, 2115-2119.

[5] a) Z. Lu, M. Shen, T. P. Yoon, J. Am. Chem. Soc. 2011, 133, $1162-1164$; b) Y.-Q. Zou, L.-Q. Lu, L. Fu, N.-J. Chang, J. Rong, J.-R. Chen, W.-J. Xiao, Angew. Chem. 2011, 123, 7309-7313; Angew. Chem. Int. Ed. 2011, 50, 7171-7175; c) M. Rueping, D. Leonori, T. Poisson, Chem. Commun. 2011, 47, 9615-9617; d) S Maity, M. Zhu, R. S. Shinabery, N. Zheng, Angew. Chem. 2012 124, 226-230; Angew. Chem. Int. Ed. 2012, 51, 222-226.

[6] a) A. E. Hurtley, M. A. Cismesia, Mi. A. Ischay, T. P. Yoon, Tetrahedron 2011, 67, 4442-4448; b) S. Lin, M. A. Ischay, C. G. Fry, T. P. Yoon, J. Am. Chem. Soc. 2011, 133, 19350-19353.

[7] For selected recent examples: a) L. Furst, B. S. Matsuura, J. M. R. Narayanam, J. W. Tucker, C. R. J. Stephenson, Org. Lett. 2010, 12, 3104-3107; b) P. V. Pham, D. A. Nagib, D. W. C. MacMillan, Angew. Chem. 2011, 123, 6243-6246; Angew. Chem. Int. Ed. 2011, 50, 6119-6122; c) J. D. Nguyen, J. W. Tucker, M. D. Konieczynska, C. R. J. Stephenson, J. Am. Chem. Soc. 2011, 133, 4160-4163; d) M. Rueping, S. Zhu, R. M. Koenigs, Chem. Commun. 2011, 47, 12709-12711; e) A. McNally, C. K Prier, D. W. C. MacMillan, Science 2011, 334, 114-117; f) D. Kalyani, K. B. McMurtrey, S. R. Neufeldt, M. S. Sanford, J. Am. Chem. Soc. 2011, 133, 18566; g) D. A. Nagib, D. W. C. MacMillan, Nature 2011, 480, 224-228.

[8] For the formation of C-P bonds, see: a) D. P. Hari, B. König, Org. Lett. 2011, 13, 3852-3855; b) M. Rueping, S. Zhu, R. M Koenigs, Chem. Commun. 2011, 47, 8679-8681. For the formation of $\mathrm{C}-\mathrm{S}$ bonds, see: Y. Cheng, J. Yang, Y. Qu, P. Li, Org. Lett. 2011, 14, 98-101. For the formation of $\mathrm{C}-\mathrm{N}$ bonds, see: J. Xuan, Y. Cheng, J. An, L.-Q. Lu, X.-X. Zhang, W.-J. Xiao, Chem. Commun. 2011, 47, 8337-8339.

[9] a) D. A. Nicewicz, D. W. C. MacMillan, Science 2008, 322, 77 80 ; b) D. A. Nagib, M. E. Scott, D. W. C. MacMillan, J. Am. Chem. Soc. 2009, 131，10875-10877; c) H.-W. Shih, M. N. Vander Wal, R. L. Grange, D. W. C. MacMillan, J. Am. Chem. Soc. 2010, 132, 13600-13603; d) M. Neumann, S. Füldner, B. König, K. Zeitler, Angew. Chem. 2011, 123, 981-985; Angew. Chem. Int. Ed. 2011, 50, 951-954.

[10] For seminal and recent examples of UV-light-promoted enantioselective photocatalytic reactions, see: a) A. Bauer, F. Westkämper, S. Grimme, T. Bach, Nature 2005, 436, 1139-1140; b) C. Müller, A. Bauer, M. M. Maturi, M. C. Cuquerella, M. A. Miranda, T. Bach, J. Am. Chem. Soc. 2011, 133, 16689-16697. For a review on enantioselective photocatalysis using hydrogenbonding templates, see: c) C. Müller, T. Bach, Aust. J. Chem. 2008, 61, 557-564.

[11] a) A. Atyaoui, L. Bousselmi, H. Cachet, P. Pu, E. M. M. Sutter, $J$. Photochem. Photobiol. A 2011, 224, 71-79; b) F. Spadavecchia, G. Cappelletti, S. Ardizzone, C. L. Bianchi, S. Cappelli, C. Oliva, P. Scardi, M. Leoni, P. Fermo, Appl. Catal. B 2010, 96, 314-322; c) M. K. Seery, R. George, P. Floris, S. C. Pillai, J. Photochem. Photobiol. A 2007, 189, 258-263; d) J. Tang, J. Ye, Angew. Chem. 2004, 116, 4563-4566; Angew. Chem. Int. Ed. 2004, 43, $4463-$ 4466.

[12] An active area of current research is the use of inorganic semiconductors as photocatalysts for water splitting and hydrogen generation. For a recent review, see: a) X. Chen, S. S. Mao, Chem. Rev. 2007, 107, 2891-2959; b) R. M. Navarro Yerga, M. C. Álvarez-Galván, F. del Valle, J. A. Villoria de La Mano,
J. L. G. Fierro, ChemSusChem 2009, 2, 471-485; c) H. Xu, R. Q. Zhang, A. N. C. Ng, A. B. Djurišić, H. T. Chan, W. K. Chan, S. Y. Tong, J. Phys. Chem. C 2011, 115, 19710-19715; d) M. Antoniadou, V. M. Daskalaki, N. Balis, D. I. Kondarides, C. Kordulis, P. Lianos, Appl. Catal. B 2011, 107, 188-196.

[13] a) H. Kisch, W. Schindler, J. Photochem. Photobiol. A 1993, 103, 257-264; b) H. Kisch, W. Linder, Chem. Unserer Zeit 2001, 35, 250-257; c) M. Gärtner, H. Kisch, Photochem. Photobiol. Sci. 2007, 6, 159-164; d) N. Zeug, J. Bücheler, H. Kisch, J. Am. Chem. Soc. 1985, 107, 1459-1465; e) W. Hetterich, H. Kisch, Chem. Ber. 1987, 121, 15-20.

[14] L. Cermenati, C. Richter, A. Albini, Chem. Commun. 1998, 805 806.

[15] For selective examples using metal-organic frameworks and polymers, see: a) Z. Xie, C. Wang, K. E. deKrafft, W. Lin, J. Am. Chem. Soc. 2011, 133, 2056-2059; b) C. Wang, Z. Xie, K. E. deKrafft, W. Lin, J. Am. Chem. Soc. 2011, 133, 13445-13454.

[16] For selective examples using organic semiconductors, see: a) F. Su, S. C. Mathew, L. Möhlmann, M. Antonietti, X. Wang, S. Blechert, Angew. Chem. 2011, 123, 683-686; Angew. Chem. Int. Ed. 2011, 50, 657-660; b) F. Su, S. C. Mathew, G. Lipner, X. Fu, M. Antonietti, S. Blechert, X. Wang, J. Am. Chem. Soc. 2010, 132, 16299-16301.

[17] For selected recent reviews on organocatalysis, see: a) S. Bertelsen, K. A. Jørgensen, Chem. Soc. Rev. 2009, 38, 21782189; b) B. List, Top. Curr. Chem. 2010, 291, 1-456 (Asymmetric Organocatalysis); c) Chem. Rev. 2007, 107, 5413-5883 (special issue on organocatalysis).

[18] For a recent example combining organocatalysis and UV light/ $\mathrm{TiO}_{2}$ photocatalyis, see: X.-H. Ho, M.-J. Kang, S.-J. Kim, E. D. Park, H.-Y. Jang, Catal. Sci. Technol. 2011, 1, 923-926.

[19] P25 Degussa with an anatase/rutile ratio of 80:20 was used.

[20] a) P. Roy, S. Berger, P. Schmuki, Angew. Chem. 2011, 123, 29562995; Angew. Chem. Int. Ed. 2011, 50, 2904-2939; b) S. Higashimoto, N. Kitao, N. Yoshida, T. Sakura, M. Azuma, H. Ohue, Y. Sakata, J. Catal. 2009, 266, 279-285; c) The visible light absorption was attributed to surface deposits of organic material on $\mathrm{TiO}_{2}$.

[21] a) S. U. M. Khan, M. Al-Shahry, W. B. Ingler, Jr., Science 2002, 297, 2243-2245; b) X. Chen, L. Liu, P. Y. Yu, S. S. Maol, Science 2011, 331, 746-750.

[22] S. Füldner, R. Mild, H. I. Siegmund, J. A. Schroeder, M. Gruber, B. König, Green Chem. 2010, 12, 400-406.

[23] L. Xiong, F. Yang, L. Yan, N. Yan, X. Yang, M. Qiu, Y. Yu, J. Phys. Chem. Solids 2011, 72, 1104-1109.

[24] D. Chatterjee, V. R. Patnama, A. Sikdar, P. Joshi, R. Misra, N. N. Rao, J. Hazard. Mater. 2008, 156, 435-441.

[25] A. Pfitzner, P. Pohla, Z. Anorg. Allg. Chem. 2009, 635, 11571159.

[26] M. Hopfner, H. Weiss, D. Meissner, F. W. Heinemann, H. Kisch, Photochem. Photobiol. Sci. 2002, 1, 696-703.

[27] Procedure according to ref. [9a]; for details please see the Supporting Information.

[28] H. Kisch, Adv. Photochem. 2001, 26, 93-143.

[29] The flat band potential of $\mathrm{PbBiO}_{2} \mathrm{Br}$ in acetonitrile has not been determined. The expected shift of the potential is +0.5 to $+1.0 \mathrm{~V}$ in acetonitrile compared to that in water, $\mathrm{pH}$ 7. This would be sufficient for the observed transformations. The potentials of $\mathrm{PbBiO}_{2} \mathrm{Br}$ in water were determined to $1.67 \mathrm{~V}$ for the valence band and $-0.80 \mathrm{~V}$ for the conduction band.

[30] For the redox potential of Texas-Red, see: M. Torimura, S. Kurata, K. Yamada, T. Yokumaku, Y. Kamagata, T. Kanagawa, R. Kurane, Anal. Sci. 2001, 17, 155-160.

[31] For recent reviews on dehydrogenative coupling using oxidation reagents: a) C.-J. Li, Acc. Chem. Res. 2009, 42, 335-344; b) C. J. Scheuermann, Chem. Asian J. 2010, 5, 436-451; c) C. S. Yeung, V. M. Dong, Chem. Rev. 2011, 111, 1215-1292. 


\section{Angewandte}

Communications

[32] a) A. G. Condie, J.-C. González-Gómez, C. R. J. Stephenson, J. Am. Chem. Soc. 2010, 132, 1464; b) M. Rueping, C. Vila, R. M. Koenigs, K. Poscharny, D. C. Fabry, Chem. Commun. 2011, 47, $2360-2362$.

[33] a) Y. Pan, C. W. Kee, L. Chen, C.-H. Tan, Green Chem. 2011, 13 , $2682-2685$; b) Y. Pan, S. Wang, C. W. Kee, E. Dubuisson, Y Yang, K. P. Loh, C.-H. Tan, Green Chem. 2011, 13, 3341-3344.

[34] Klussmann et al. reported the slow racemization of the products under their oxidative reaction conditions: A. Sud, D. Sure- shkumarz, M. Klussmann, Chem. Commun. 2009, 3169-3171. Our stereochemical analysis also reveals only low ee values as similarly noted in previous reports by Rueping (see Ref. [32b]) and Tan (see Ref. [33a]).

[35] For a recent paper on the calculation of flat band potentials of semiconductor oxides, see: M. C. Toroker, D. K. Kanan, N. Alidoust, L. Y. Isseroff, P. Liaob, E. A. Carter, Phys. Chem. Chem. Phys. 2011, 13, 16644-16654. 